\title{
Lo más fresco de la Florida: Melones (cantaloupes) ${ }^{1}$
}

\author{
Claudia Peñuela ${ }^{2}$
}

\section{Datos nutricionales}

Los melones (cantaloupes) de Florida son:

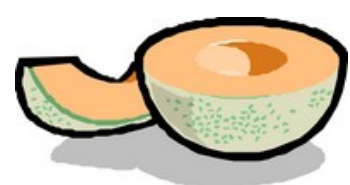

$\checkmark$ Altos en vitamina A. La vitamina A ayuda a mantener

una visión normal, una piel saludable y a proteger

contra las infecciones.

$\checkmark$ Altos en vitamina $C$. La vitamina $C$ ayuda a curar las

cortadas, heridas y a mantener saludables los dientes y encías.

$\checkmark$ Una buena fuente de potasio. El potasio ayuda a controlar la presión arterial.

$\checkmark$ Naturalmente libres de colesterol y bajos en sodio.

Nota: Este documento se refiere a melones variedad cantaloupe. Existen otras variedades de melones como casaba y honeydew que no están incluidos en este documento.

\begin{tabular}{|c|}
\hline Amount Per Serving \\
\hline \multirow[t]{2}{*}{ Calories 60} \\
\hline \\
\hline Total Fat $0 \mathrm{~g}$ \\
\hline Saturated Fat $0 \mathrm{~g}$ \\
\hline Trans Fat \\
\hline Cholesterol Omg \\
\hline Sodium $28 \mathrm{mg}$ \\
\hline Total Carbohydrate $16 \mathrm{~g}$ \\
\hline Dietary Fiber $2 g$ \\
\hline Sugars $14 \mathrm{~g}$ \\
\hline Protein 1g \\
\hline $120 \% \cdot$ Vitamin C \\
\hline $2 \% \cdot$ Iron \\
\hline $\begin{array}{l}\text { "Percent Daly Values are based on a } 2,000 \text { calone diet. } \\
\text { Your dally values may be higher or lower depending on } \\
\text { your calore needs. }\end{array}$ \\
\hline www.NutritionData.com \\
\hline
\end{tabular}

\section{¿Por qué comprar localmente?}

El Departamento de Agricultura de los Estados Unidos (USDA, por sus siglas en inglés) estima que el promedio de viaje de los productos agrícolas desde su origen hasta los mercados locales del agricultor es de solo $\mathbf{5 0}$ millas, comparado con $\mathbf{2 , 0 0 0}$ millas hasta los supermercados.

Compre localmente y obtenga estos beneficios:

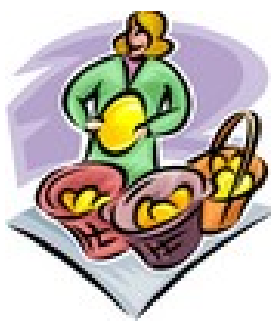

Frescura y nutrición. Las frutas y verduras cosechadas en su punto tienen mejor sabor y características nutricionales.

Social/cultural. Ayuda a la comunidad a estar consciente de la importancia de la agricultura.

$>$ Ambiental. Protege los recursos naturales como espacios verdes, fauna, flora, agua, aire y suelos.

$>$ Económico. Promueve la fuerza laboral local.

\section{¿Dónde se cosechan los melones de Florida?}

Los melones se cosechan en todo el estado, pero la mayoría de los cultivos están en el centro de Florida. Florida es un importante productor gracias a las estaciones de clima templado, soleado y libre de heladas.

1. Este documento FCS 8878-Span, es uno de una serie del Departamento de Ciencias de la Familia, la Juventud y la Comunidad, Servicio de Extensión Cooperativa de la Florida, Instituto de Alimentos y Ciencias Agrícolas, Universidad de la Florida. Fecha de primera publicación: agosto 2009. Visite nuestro sitio web EDIS en http://edis.ifas.ufl.edu.

2. Claudia P eñuela, asistente e $\mathrm{n}$ n utrición-EFNEP, Departamento d e C iencias de 1 a F amilia, 1 a J uventud y 1 a C omunidad, S ervicio de E xtensión Cooperativa, Instituto de Alimentos y Ciencias Agrícolas, Universidad de la Florida, Gainesville, Florida 32611. 


\section{¿Cuándo puede comprar melones en Florida?}

Puede comprar melones desde marzo hasta julio. ¡Durante cinco meses del año!

\begin{tabular}{|l|l|l|l|l|l|l|l|l|l|l|l|} 
ENE & FEB & MAR & ABR & MAY & JUN & JUL & AGO & SEP & OCT & NOV & DIC \\
\hline
\end{tabular}

\section{Seleccione}

$\checkmark$ Melones con olor dulce, blandos en la parte superior del tallo y de corteza color amarrillo cremoso. Esto indica que están en su punto de madurez y sabor.

$\checkmark$ Melones simétricamente bien formados y pesados de acuerdo a su tamaño.

$\checkmark$ Melones sin magulladuras, puntos blandos, ni cortezas rajadas o abiertas.

Siga estos consejos: Lave cualquier variedad de melón antes de cortarlo. Después de cortado, colóquelo en contenedores sellados y refrigere.

\section{Melones Frescos de la Florida: del mercado a la mesa}

\section{Raspado de fruta}

$2 \frac{2}{3}$ tazas de melón en trozos, sin semillas y pelado

$12 / 3$ tazas de kiwi picado (opcional)

2-3 cucharadas de azúcar

2 cucharadas de jugo de lima

2 tazas de agua

hielo

\section{Rinde: 4 Porciones}

1. En una licuadora mezcle la fruta, azúcar y jugo de lima hasta obtener un puré.

2. Combine la mezcla de fruta con el agua en una jarra.

3. Si prefiere, cuele para eliminar la pulpa.

4. Cubra y refrigere durante una semana.

5. Sírvalo bien mezclado y en vasos altos con hielo si desea coloque menta.

*Información nutricional por porción (1/4 de receta) 239g:

Calorías: 60 cal; Grasa Total 0g; Sodio 20mg; Carbohidratos Totales 16g; Fibra 1g; Proteína 1g; Vitamina A 70\%; Vitamina C 70\%; Calcio 2\%; Hierro 2\%. *El \% del valor diario de vitamina $A$, vitamina $\mathrm{C}$, calcio y hierro está basado en una dieta de 2,000 calorías.

Adaptado de: Pictorial Recipes, Lynn Myers Steele, 2000, Oregon Family Nutrition Program, Oregon State University Extension Service; $y$ http://recipefinder.nal.usda.gov/index.php?mode=display\&rec id=57

salsa de melón

2 tazas de melón en trozos, sin semillas 1 taza de pepino en trozos, sin semillas y pelado $1 / 4$ taza de cebolla roja o blanca, picada 2 cucharadas de cilantro o menta (opcional), picada $1 / 2$ - 1 chile jalapeño sin semilla y finamente picado o salsa picante al gusto $1 / 4$ taza de jugo de lima o limón 1 cucharada de azúcar, blanca o morena

Adaptado de: Montana Extension Nutrition Education Program, Website Recipes, Montana State University Extension Service; y http://recipefinder.nal.usda.gov/index.php?mode=display\&rec id=486

\section{Rinde: 12 Porciones}

1. En un recipiente, mezcle todos los ingredientes.

2. Pruebe, sazone con más jugo de lima o limón y azúcar según sea el caso.

3. Cubra y refrigere por al menos 30 minutos. Sirva con pollo o pescado asado o a la parrilla.

Advertencia. Los chiles contienen aceites que pueden irritar los ojos y la piel. Debe usar guantes de cocina o lavarse las manos inmediatamente después de tocarlos. No se toque los ojos.

Información nutricional por porción (45g): Calorías 15 cal; Grasa Total 0g; Sodio 0mg; Carbohidratos Totales 4g; Proteína 0g. 